\title{
Risk factors for radiation pneumonitis in lung cancer patients with subclinical interstitial lung disease after thoracic radiation therapy
}

Fangjuan $\mathrm{Li}^{1 \dagger}$, Hui Liu ${ }^{1 \dagger}$, Hongyu $\mathrm{Wu}^{1 \dagger}$, Shixiong Liang ${ }^{2^{*+}}$ and Yaping $\mathrm{Xu}^{1^{*+}}$

\begin{abstract}
Background: Previous studies have found that patients with subclinical interstitial lung disease (ILD) are highly susceptible to developing radiation pneumonitis (RP) after thoracic radiation therapy. In the present study we aimed to evaluate the incidence of and risk factors for RP after thoracic intensity-modulated radiation therapy in lung cancer patients with subclinical ILD.

Methods: We retrospectively analyzed data from lung cancer patients with subclinical ILD who were treated with thoracic intensity-modulated radiation therapy with a prescribed dose of $\geq 50$ Gy in our institution between January 2016 and December 2017.

Results: Eighty-seven consecutive lung cancer patients with subclinical ILD were selected for the study. The median follow-up period was 14.0 months. The cumulative incidence of grades $\geq 2$ and $\geq 3 \mathrm{RP}$ at one year was $51.0 \%$ and $20.9 \%$, respectively. In the multivariate analysis, a mean lung dose $\geq 12$ Gy was a significant risk factor for grade $\geq 2 \mathrm{RP}$ $(p=0.049)$. Chemotherapy with gemcitabine in the past, $\mathrm{V} 5 \geq 50 \%$, and subclinical ILD involving $\geq 25 \%$ of the lung volume were significantly associated with grade $\geq 3 \operatorname{RP}(p=0.046, p=0.040$, and $p=0.024$, respectively).

Conclusion: Mean lung dose is a significant risk factor for grade $\geq 2$ RP. Lung cancer patients who have received chemotherapy with gemcitabine in the past, V5 $\geq 50 \%$, and those with subclinical ILD involving $\geq 25 \%$ of lung volume have an increased risk of grade $\geq 3$ RP in lung cancer patients with subclinical ILD.
\end{abstract}

Keywords: Lung cancer, RP, ILD

\section{Introduction}

Radiation pneumonitis (RP) is a common complication of radiotherapy for lung cancers. The incidence of symptomatic RP is approximately $15-40 \%$ [1]. Dose-volume

\footnotetext{
*Correspondence: shixliang@vip.sina.com; xuyaping1207@163.com ${ }^{\dagger}$ Shixiong Liang and Yaping Xu have contributed equally to this article ${ }^{\dagger}$ Fangjuan Li, Hui Liu, and Hongyu Wu have contributed equally to this article and should be regarded as co-first authors

1 Department of Radiation Oncology, Shanghai Pulmonary Hospital,

Tongji University School of Medicine, No. 507 Zhengmin Road, Yangpu District, Shanghai 200433, People's Republic of China

${ }^{2}$ Department of Radiation Oncology, Affiliated Cancer Hospital of Guangxi Medical University, Cancer Institute of Guangxi Zhuang Autonomous Region, Nanning, Guangxi, People's Republic of China
}

histogram-based dosimetric parameters, including the percentage of lung volume receiving a dose of $\geq 20$ Gy (V20), the mean lung dose (MLD), treatment factors such as sequential or concurrent chemotherapy schedules, tumor factors such as tumor size and location, and patient factors including poor pulmonary function and concomitant disease are predictive markers for RP [2-9].

Subclinical interstitial lung disease (ILD) has a higher incidence in patients with lung cancer than in the general population [10]. Previous studies found that patients with subclinical ILD were more susceptible to developing RP after thoracic radiation therapy (TRT) [10-16].

Few studies have investigated the correlation between subclinical ILD and RP. There have been no reports on

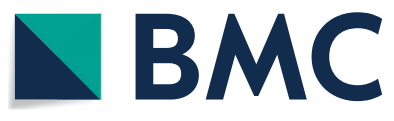

(c) The Author(s) 2021. Open Access This article is licensed under a Creative Commons Attribution 4.0 International License, which permits use, sharing, adaptation, distribution and reproduction in any medium or format, as long as you give appropriate credit to the original author(s) and the source, provide a link to the Creative Commons licence, and indicate if changes were made. The images or other third party material in this article are included in the article's Creative Commons licence, unless indicated otherwise in a credit line to the material. If material is not included in the article's Creative Commons licence and your intended use is not permitted by statutory regulation or exceeds the permitted use, you will need to obtain permission directly from the copyright holder. To view a copy of this licence, visit http://creativecommons.org/licenses/by/4.0/. The Creative Commons Public Domain Dedication waiver (http://creativeco mmons.org/publicdomain/zero/1.0/) applies to the data made available in this article, unless otherwise stated in a credit line to the data. 
the incidence of and risk factors for RP in lung cancer patients with subclinical ILD after intensity-modulated radiation therapy (IMRT). This single-institution study was conducted to determine the incidence of and risk factors for RP after IMRT in lung cancer patients with subclinical ILD.

\section{Materials and methods \\ Patients}

Lung cancer patients with subclinical ILD who were treated with thoracic IMRT in our institution between January 2016 and December 2017 were retrospectively analyzed. The inclusion criteria were as follows: (1) patients diagnosed with lung cancer by histology or cytology; (2) interstitial lung changes on high-resolution Computed Tomography (HRCT) images before radiotherapy and chemotherapy; (3) Karnofsky performance status scale $\geq 70$ and ability to endure IMRT at a total dose of the equivalent dose in $2.0 \mathrm{~Gy} /$ (fraction per day) (EQD2) $\geq 50$ Gy; (4) age $\geq 18$ years; (5) no other serious medical conditions; (6) RT with concurrent or sequential chemotherapy; (7) no TRT received previously; (8) thoracic CT images available for evaluation before and after TRT; (9) follow-up time of more than six months for patients without RP; and (10) patients were inoperable. Individuals with TRT terminated due to non-radiotherapy-related complications for more than seven days were excluded.

\section{Radiotherapy}

All patients underwent a planning CT scan when immobilized in a supine position with their arms raised in a customized vacuum-lock mold. Simulation CT images were taken at $0.5 \mathrm{~cm}$ increments over the region of interest. Treatment planning was performed using an ADAC Pinnacle $^{\mathrm{TM}}$ (Philips Medical Systems) system. Treatment consisted of 6 or $10 \mathrm{MV}$ photon thoracic IMRT using a Siemens Artiste (Oncology Care Systems, Siemens Medical Solutions, CA, USA) digital linear accelerator. The target volumes were set manually by experienced radiation oncologists focused on lung cancer.

The gross tumor volume (GTV) was defined as the volume of a primary tumor demonstrated by a CT scan and metastatic lymph nodes based on pretreatment chest CT scan and/or [18F]-fluorodeoxyglucose positron emission tomography/CT images, bronchoscopy or other approaches. The clinical target volume (CTV) was typically a $0.6-0.8 \mathrm{~cm}$ expansion of the GTV, including the primary tumor in the lung and the drainage area of metastatic lymph nodes. The CTV of prophylactic postoperative radiotherapy was determined based on postoperative pathology, including the bronchial stump, ipsilateral hilar, and drainage area of tumor-positive lymph nodes. The planning target volume (PTV) was defined by adding margins at the discretion of radiation oncologists. The margins were typically $0.5-1.0 \mathrm{~cm}$, depending on respiratory motion and patient fixation. The goal of the therapy was to deliver the prescribed dose to at least $95 \%$ of the PTV, while meeting normal tissue constraints. The total dose was $\geq 50.0 \mathrm{~Gy}$, and was generally delivered at 2.0$3.0 \mathrm{~Gy} /$ (fraction per day), for five fractions per week. If the lung dose exceeded the safety range, the total dose was reduced as appropriate. Informed consent was obtained from all patients prior to radiotherapy. Ethical approval was obtained from the Ethical Review Committee of Shanghai Pulmonary Hospital, Tongji University School of Medicine, China.

\section{Chemotherapy}

The concurrent chemotherapy regimen consisted of platinum combined with pemetrexed, paclitaxel, docetaxel, vinorelbine, or etoposide. Patients who were older, had reached stage IV, had poor pulmonary function, anemia, abnormal liver or renal function, or who exhibited progression after first-line chemotherapy were given single-agent concurrent chemotherapy or sequential chemoradiotherapy. Chemotherapy was generally performed in four to six cycles every three to four weeks.

\section{Diagnosis of subclinical ILD}

Data from lung cancer patients with subclinical ILD detected using HRCT images who were treated with thoracic IMRT in our institution between January 2016 and December 2017 were analyzed. The diagnosis of subclinical ILD was based on pretreatment HRCT images with an axial slice thickness of $0.1 \mathrm{~cm}$ in a lung window. Reticular abnormalities, traction bronchiectasis, bilateral independent ground-glass abnormalities, honeycombing, and nonemphysematous cysts were considered to be indicative of subclinical ILD [17-19]. The diagnosis of subclinical ILD and the CT scans were evaluated independently by a radiologist and two physicians specializing in pulmonology.

\section{Follow-up}

Patients were re-evaluated at one to two months post treatment and subsequently every three months. The endpoint was the incidence of grade $\geq 2$ RP. Adverse events were graded using the Common Terminology Criteria for Adverse Events Version 4.0.

\section{Statistical analysis}

Correlations between RP and the risk factors were analyzed using Chi-square tests, Student's t-tests, or Mann-Whitney U tests for univariate analysis. Receiver operating characteristic curves were generated to 
determine the optimal cut-off value of continuous variables. Logistic regression analysis was performed to evaluate the correlations between RP and the risk factors using multivariate analysis. The cumulative incidence of RP was estimated using the Kaplan-Meier method, and differences between the groups were assessed using log-rank tests. The overall survival (OS) was defined as the interval between the date of diagnosis and the date of death or last follow-up. OS was also estimated using the KaplanMeier method. Statistical analyses were performed using IBM SPSS software 22.0 for Mac. A $p$ value less than 0.05 was considered to be statistically significant.

\section{Results}

From January 2016 to December 2017, a total of 87 consecutive lung cancer patients with subclinical ILD, aged 48 to 86 years with a median age of 67 years, were enrolled in the study. The tumor stage was determined according to the 8th edition of the Union for International Cancer Control TNM staging system for lung cancer. None of the patients had been diagnosed with ILD clinically or via lung biopsy prior to receiving chemotherapy or radiotherapy. None of the patients had received treatment with any of the currently available medicines for ILD. Seventy-six patients had received chemotherapy prior to radiotherapy. The median duration of chemotherapy was two cycles (range, $0-6$ cycles). Two patients had previously received epidermal growth factor receptor tyrosine kinase inhibitor. The characteristics of the patients are shown in Table 1.

The median follow-up time was 14.0 months (range, 1.2-58.9 months). RP was observed in 19 (21.8\%), 27 (31.0\%), 10 (11.5\%), three (3.4\%), and five (5.7\%) patients with grades 1, 2, 3, 4, and $5 \mathrm{RP}$, respectively. Radiotherapy was discontinued in eight patients because a grade $\geq 2$ $\mathrm{RP}$ occurred during radiotherapy. The characteristics of the patients for whom radiotherapy was discontinued are shown in Table 2. Five patients developed grade 5 RP; their characteristics are shown in Table 3.

The cumulative incidence of grades $\geq 2 \mathrm{RP}$ at one year was $51.0 \%$ and that of grades $\geq 3 \mathrm{RP}$ was $20.9 \%$. Although the percentage of lung volume affected in subclinical ILD did not significantly increase the cumulative incidence of grade $\geq 2$ RP $(69.4 \% v s .47 .7 \%, p=0.082$, Fig. 1a), the cumulative incidence of grade $\geq 3 \mathrm{RP}$ was significantly higher in patients with subclinical ILD involving $\geq 25 \%$ of lung volume than those with $<25 \%$ involvement of lung volume ( $46.1 \%$ vs. $16.3 \%, p=0.004$, Fig. 1b). Gemcitabine chemotherapy before radiotherapy did not significantly affect the cumulative incidence of grade $\geq 2 \mathrm{RP}(53.2 \%$ vs. $49.6 \%, p=0.525$, Fig. 1c), but the cumulative incidence of grade $\geq 3 \mathrm{RP}$ was significantly higher in patients who had
Table 1 Characteristics of the patients

\begin{tabular}{|c|c|}
\hline Factors & N (\%) \\
\hline \multicolumn{2}{|l|}{ Gender } \\
\hline Male & $81(93.1)$ \\
\hline Female & $6(6.9)$ \\
\hline \multicolumn{2}{|l|}{ Age (years) } \\
\hline$<70$ & $57(65.5)$ \\
\hline$\geq 70$ & $30(34.5)$ \\
\hline \multicolumn{2}{|l|}{ Pathological types } \\
\hline NSCLC & $57(65.5)$ \\
\hline Adenocarcinoma & $17(19.5)$ \\
\hline Squamous cell carcinoma & $24(27.6)$ \\
\hline Large cell carcinoma & $1(1.1)$ \\
\hline Unclassified NSCLC & $15(17.2)$ \\
\hline SCLC & $30(34.5)$ \\
\hline \multicolumn{2}{|l|}{ Tumor stage } \\
\hline । & $2(2.3)$ \\
\hline$\| \mathrm{A}$ & $24(27.6)$ \\
\hline$\| \mathrm{II}$ & $37(42.5)$ \\
\hline$\| I I C$ & $3(3.4)$ \\
\hline IV & $10(11.5)$ \\
\hline Postoperative & $11(12.6)$ \\
\hline \multicolumn{2}{|l|}{ Chemotherapy } \\
\hline Concurrent & $19(21.8)$ \\
\hline Sequential & $68(78.2)$ \\
\hline
\end{tabular}

NSCLC, non-small-cell lung cancer; SCLC, small-cell lung cancer

received chemotherapy with gemcitabine in the past than in those who had not (32.3\% vs. $13.3 \%, p=0.023$, Fig. $1 \mathrm{~d}$ ).

Table 4 shows the correlations between the risk factors and RP. In the univariate analysis, tumor location (upper lobe vs. middle or lower lobe) and MLD were significantly associated with grade $\geq 2 \mathrm{RP}(p=0.043$ and $p=0.024$, respectively). The risk of grade $\geq 3 \mathrm{RP}$ was higher in patients who had received chemotherapy with gemcitabine in the past, and in those who had subclinical ILD involving $\geq 25 \%$ of lung volume ( $p=0.031$ and $p=0.037$, respectively).

In the multivariate analysis, MLD $\geq 12.0$ Gy was a significant risk factor for grade $\geq 2 \mathrm{RP}(p=0.049)$. Having received chemotherapy with gemcitabine in the past, having a V5 $\geq 50 \%$, and having subclinical ILD involving $\geq 25 \%$ of the lung volume were significantly associated with grade $\geq 3 \mathrm{RP}(p=0.046, p=0.040$, and $p=0.024$, respectively). The results of a binary logistic regression analysis for RP are shown in Table 5.

The median survival time for all patients was 18.3 months (range, 4.8-84.7 months). Seventy-seven patients had died at the time of writing. The one-year, two-year, three-year OS rates were $80.0 \%, 32.0 \%$, and $25.0 \%$, respectively (Fig. 2). 
Table 2 Characteristics of patients who discontinued radiotherapy

\begin{tabular}{|c|c|c|c|c|c|c|c|c|}
\hline No & Age (years)/Gender & $\begin{array}{l}\text { Smoking } \\
\text { history (pack- } \\
\text { years) }\end{array}$ & $\begin{array}{l}\text { Pathological type/ } \\
\text { Tumor stage }\end{array}$ & $\begin{array}{l}\text { Treatment } \\
\text { modality }\end{array}$ & $\begin{array}{l}\text { Induction } \\
\text { chemotherapy } \\
\text { regimen }\end{array}$ & $\begin{array}{l}\text { Radiotherapy } \\
\text { dose (Gy/ } \\
\text { fraction) }\end{array}$ & $\begin{array}{l}\text { Percentage of lung } \\
\text { volume affected in } \\
\text { subclinical ILD (\%) }\end{array}$ & Grade of RP \\
\hline 1 & 68/Male & 40 & $\begin{array}{l}\text { Squamous cell carci- } \\
\text { noma/IIIB }\end{array}$ & RT & $\begin{array}{l}\text { Cisplatin + gemcit- } \\
\text { abine }\end{array}$ & $44.0 / 22$ & $\geq 25$ & 4 \\
\hline 2 & 77/Male & 50 & $\begin{array}{l}\text { Squamous cell carci- } \\
\text { noma/IIIB }\end{array}$ & RT & $\begin{array}{l}\text { Carboplatin + gem- } \\
\text { citabine }\end{array}$ & $49.5 / 22$ & $\geq 25$ & 5 \\
\hline 3 & 67/Male & No & $\begin{array}{l}\text { Squamous cell } \\
\text { carcinoma/post- } \\
\text { operative stump } \\
\text { recurrence }\end{array}$ & RT & $\begin{array}{l}\text { Cisplatin + gemcit- } \\
\text { abine }\end{array}$ & $24.0 / 12$ & $<25$ & 2 \\
\hline 4 & 63/Male & 80 & $\begin{array}{l}\text { Adenocarcinoma/ } \\
\text { IIIB }\end{array}$ & RT & $\begin{array}{l}\text { Cisplatin + gemcit- } \\
\text { abine }\end{array}$ & $58.0 / 29$ & $<25$ & 3 \\
\hline 5 & 65/Male & 40 & NSCLC/IIIB & RT & $\begin{array}{l}\text { Cisplatin + vinorel- } \\
\text { bine }\end{array}$ & $38.0 / 19$ & $<25$ & 4 \\
\hline 6 & 69/Male & 50 & $\begin{array}{l}\text { Squamous cell carci- } \\
\text { noma/IIIB }\end{array}$ & RT & $\begin{array}{l}\text { Carboplatin + gem- } \\
\text { citabine }\end{array}$ & $38.0 / 19$ & $\geq 25$ & 5 \\
\hline 7 & 52/Male & 60 & $\begin{array}{l}\text { Adenocarcinoma/ } \\
\text { IIIB }\end{array}$ & RT & $\begin{array}{l}\text { Cisplatin + pem- } \\
\text { etrexed }\end{array}$ & $30.0 / 15$ & $<25$ & 2 \\
\hline 8 & 67/Male & No & $\mathrm{SCLC} / \mathrm{IIIB}$ & RT & $\begin{array}{l}\text { Carbopl- } \\
\text { atin + etoposide }\end{array}$ & $40.0 / 20$ & $<25$ & 2 \\
\hline
\end{tabular}

$\mathrm{RP}$, radiation pneumonitis; ILD, interstitial lung disease; RT, radiation therapy; NSCLC, non-small-cell lung cancer; SCLC, small-cell lung cancer

\section{Discussions}

Previous studies have identified a $4 \%-11 \%$ prevalence of subclinical ILD in high-risk populations undergoing CT screening for lung cancer [20]. A few studies found that the incidence of grade $\geq 2 \mathrm{RP}$ and grade $\geq 3 \mathrm{RP}$ was significantly higher in patients with subclinical ILD than in those without subclinical ILD after stereotactic body radiotherapy (SBRT) [11, 20]. Yamaguchi and colleagues [21] reported that although subclinical ILD showed no significant correlation with grade $\geq 2 \mathrm{RP}$, three patients with extensive bilateral RP had subclinical ILD prior to receiving radiotherapy. Several studies have also found a significantly higher incidence of RP after three-dimensional conformal radiotherapy (3D-CRT) in lung cancer patients with subclinical ILD [10, 12]. Two of three patients with grade 5 RP had subclinical ILD in multiple lobes [10].

Data on the correlation between subclinical ILD and $R P$ in patients after IMRT are limited. Our previous study revealed that subclinical ILD was a risk factor for grade $\geq 3$ RP in patients with small-cell lung cancer after TRT [13]. In this single-institution retrospectively study, the cumulative incidence of grade $\geq 2 \mathrm{RP}$ was $51.7 \%$, and that of grade $\geq 3 \mathrm{RP}$ was $20.7 \%$ in lung cancer patients with subclinical ILD after IMRT. The incidence of grade $\geq 2$ RP in this study was consistent with that reported by previous studies, and the rate of grade $\geq 3 \mathrm{RP}$ in this study was lower than that reported previously for patients with subclinical ILD following 3D-CRT [10, 12]. Sanuki et al. [22] found the rate of grade $\geq 3 \mathrm{RP}$ increased from 3 to $26 \%$ in patients with subclinical ILD. Niska JR and colleagues [23] presented two cases of fatal RP in patients with limited subclinical ILD. Individuals with subclinical ILD were at higher risk of RP [16]. Recently, a study reported that proton therapy might be helpful for reducing acute and fatal complications in non-small-cell lung cancer (NSCLC) patients with idiopathic pulmonary fibrosis [24].

Although an association between preexisting subclinical ILD and RP has been reported, little is known about the relationship between $\mathrm{RP}$ and the $\mathrm{CT}$ radiological features of subclinical ILD. Some studies have graded subclinical ILD, in order to evaluate its severity. However, there is no consensus on the definition of subclinical ILD grading. Washko's scoring criteria are commonly used [10,20,21, 25, 26]. Glick et al. [20] reported that Washko's score is associated with grade $\geq 2$ RP using a univariate analysis; however, there was no statistical difference identified using a multivariate analysis. Another study found that cases that exhibited honeycombing had a high potential for fatality due to severe RP after SBRT [27]. In this study, we explored the correlations between the distribution, morphology, and percentage of lung volume affected in subclinical ILD, and RP. Only the percentage of lung volume affected in subclinical ILD when it was $\geq 25 \%$ was significantly associated with the risk of grade $\geq 3$ RP. It is easier to evaluate the severity of subclinical ILD by indirectly measuring the percentage of lung volume affected based on pretreatment HRCT images than 


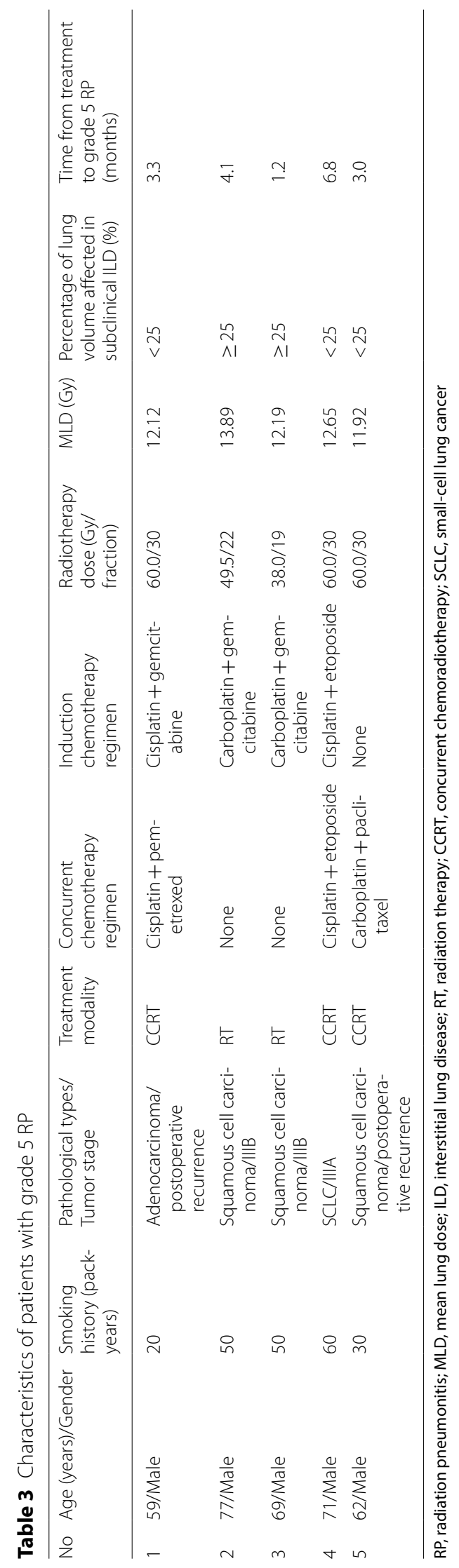


a

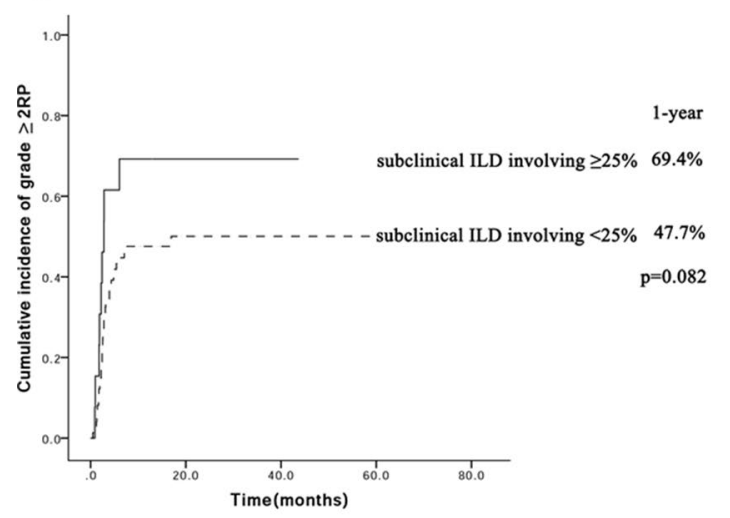

c

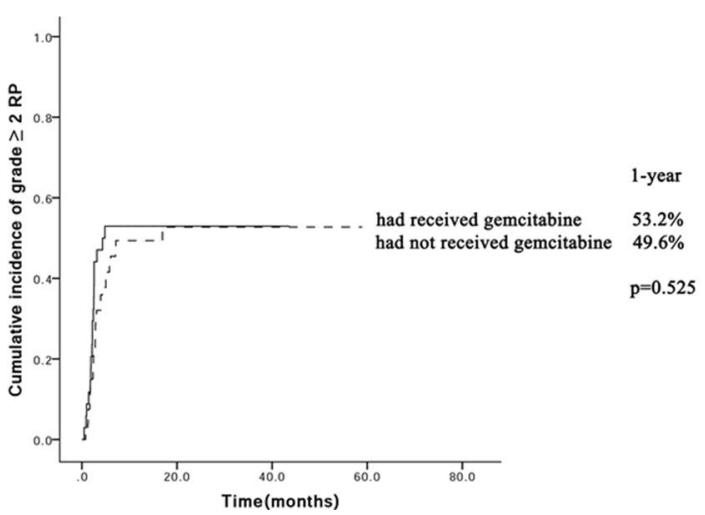

b

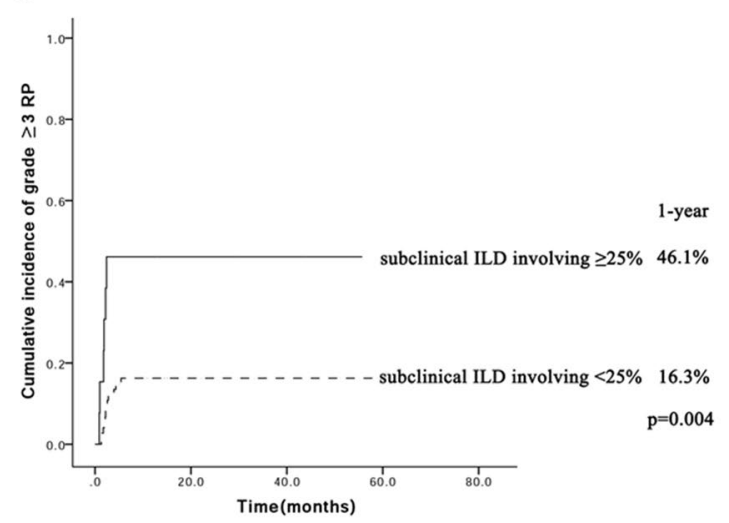

d

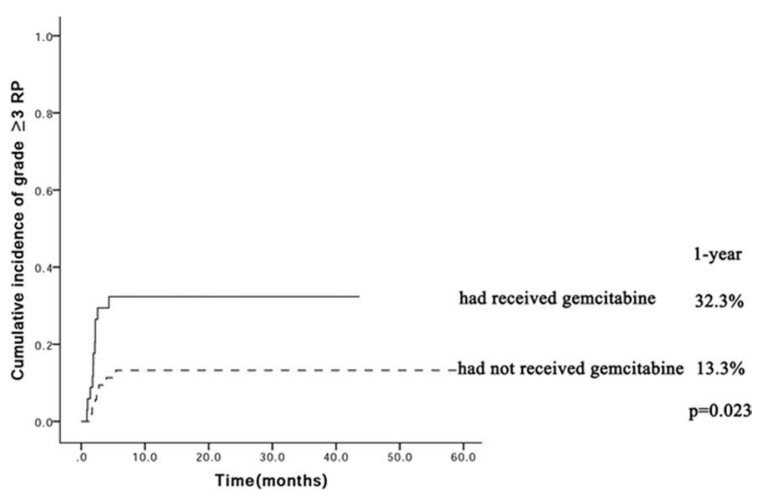

Fig. 1 a Cumulative incidence of grade $\geq 2$ RP in patients with different involvement volumes of subclinical ILD; $\mathbf{b}$ Cumulative incidence of grade $\geq 3$ RP in patients with different involvement volumes of subclinical ILD; $\mathbf{c}$ Cumulative incidence of grade $\geq 2$ RP in patients who had (solid line) or had not (dashed line) received chemotherapy with gemcitabine in the past; $\mathbf{d}$ Cumulative incidence of grade $\geq 3 \mathrm{RP}$ in patients who had (solid line) or had not (dashed line) received chemotherapy with gemcitabine in the past

by using the scoring criteria, which makes it easier to identify individuals who have a high risk of RP.

Dosimetric parameters are closely correlated to the incidence of RP. We found that MLD is a significant risk factor for grade $\geq 2 \mathrm{RP}$, and patients with a V $5 \geq 50 \%$ have an increased risk of grade $\geq 3$ RP. Previous studies have also found that MLD was a predictor of RP in patients with subclinical ILD after SBRT and 3D-CRT $[12,20,21]$. A retrospective analysis reported that V5 was significantly associated with the occurrence of RP grade progression after carbon-ion radiotherapy for NSCLC with ILD [28]. Onishi et al. [29] found that a $\mathrm{V} 20 \geq 10 \%$ is a major risk factor for severe RP in stage I NSCLC patients with subclinical ILD. In the present study, no correlation was observed between the incidence of RP and V20. This lack of correlation may have arisen because we strictly controlled the limits of V20. Other studies have also failed to find a correlation between dosimetric parameters and RP in patients with subclinical ILD after 3D-CRT, SBRT and IMRT [10, 13, 30].

Gemcitabine is a first-line chemotherapy drug commonly used in advanced NSCLC. Some studies have reported that gemcitabine produces pulmonary toxicity. The use of concurrent radiotherapy and gemcitabine after induction with gemcitabine and carboplatin significantly increased the incidence of grade $\geq 3 \mathrm{RP}$ up to 31.6\% [3]. In 2010, the Quantitative Analyses of Normal Tissue Effects in the Clinic group indicated that gemcitabine is associated with a higher risk of pulmonary toxicity when used concurrently with thoracic RT [2]. Leprieur and colleagues [7] found that induction chemotherapy with gemcitabine before radiotherapy was associated with a high incidence of RP.

There have been no studies to date that evaluated the safety of chemotherapy with gemcitabine before TRT in patients with ILD or subclinical ILD. In the current study, chemotherapy with gemcitabine before radiotherapy 
Li et al. Radiat Oncol ～(2021) 16:70

Page 7 of 11

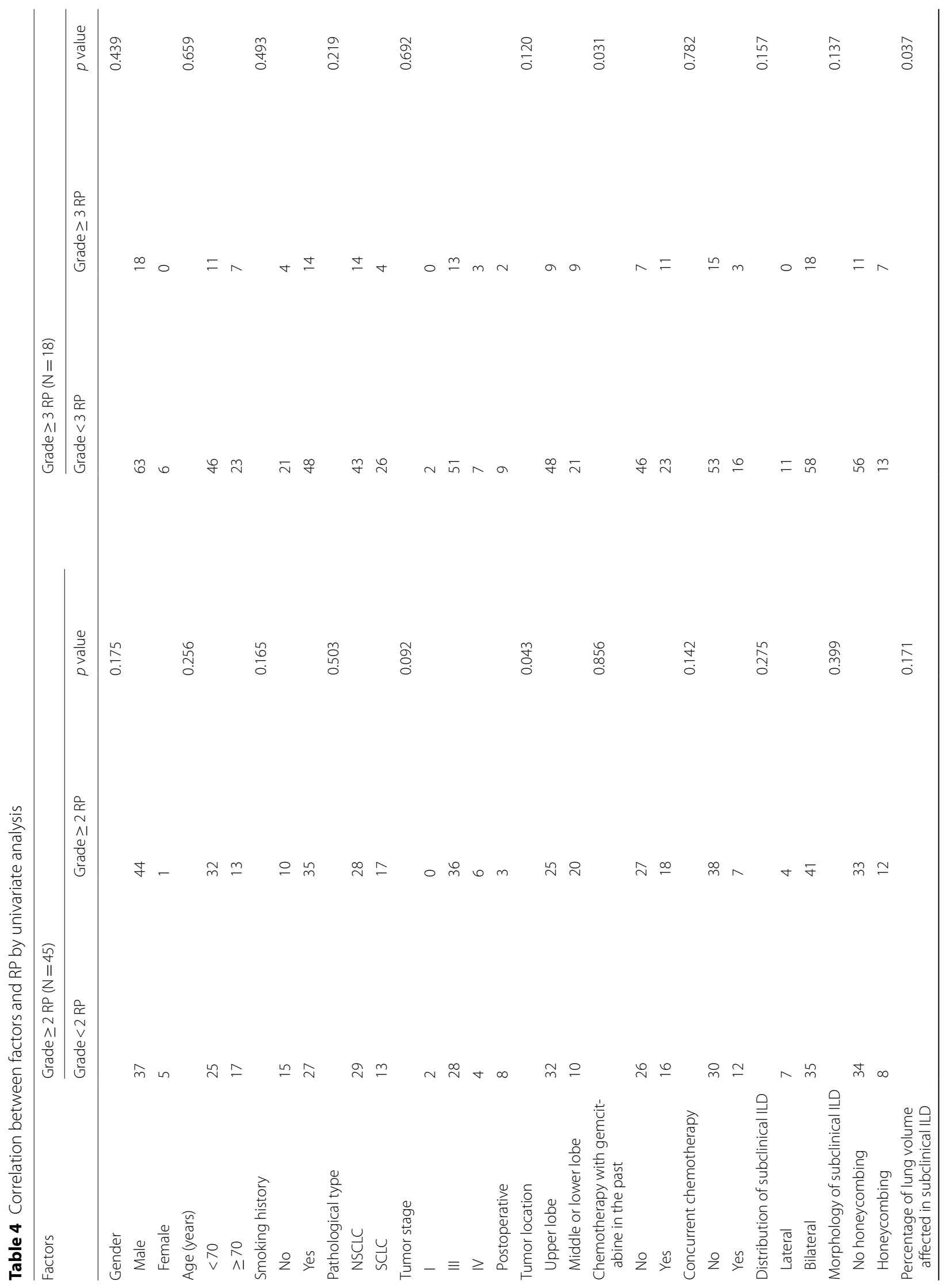




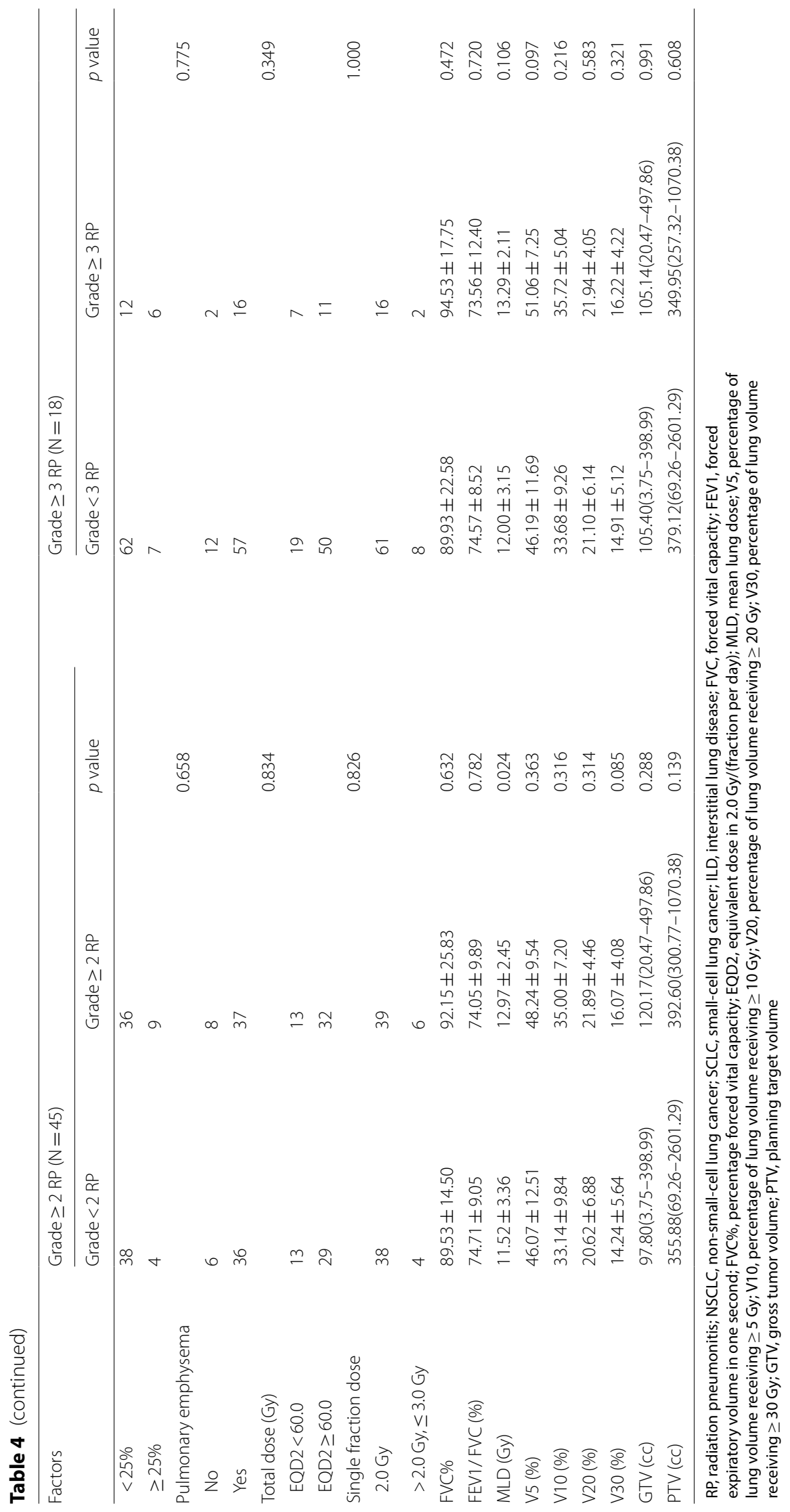


Table 5 Correlation between risk factors and RP using binary logistic regression analysis

\begin{tabular}{|c|c|c|c|c|c|c|}
\hline \multirow[t]{2}{*}{ Factors } & \multicolumn{3}{|l|}{ Grade $\geq 2$ RP } & \multicolumn{3}{|c|}{ Grade $\geq 3$ RP } \\
\hline & Odds ratio (OR) & $95 \% \mathrm{Cl}$ & $p$ value & OR & $95 \% \mathrm{Cl}$ & $p$ value \\
\hline MLD ( $\geq 12.0$ Gy vs. $<12.0$ Gy) & 2.480 & $1.006-6.113$ & 0.049 & - & - & - \\
\hline Tumor located in lower lobe & 2.311 & $0.898-5.943$ & 0.082 & - & - & - \\
\hline Chemotherapy with gemcitabine in the past & - & - & - & 3.209 & $1.018-10.113$ & 0.046 \\
\hline V5 ( $\geq 50 \%$ vs. $<50 \%)$ & - & - & - & 3.429 & $1.056-11.140$ & 0.040 \\
\hline $\begin{array}{l}\text { Percentage of lung volume affected in subclinical } \\
\qquad \mathrm{LD} \geq 25 \%\end{array}$ & - & - & - & 4.861 & $1.237-19.104$ & 0.024 \\
\hline
\end{tabular}

$\mathrm{RP}$, radiation pneumonitis; MLD, mean lung dose; $\mathrm{V} 5$, percentage of lung volume receiving $\geq 5 \mathrm{~Gy}$; ILD, interstitial lung disease; $\mathrm{Cl}$, confidence interval

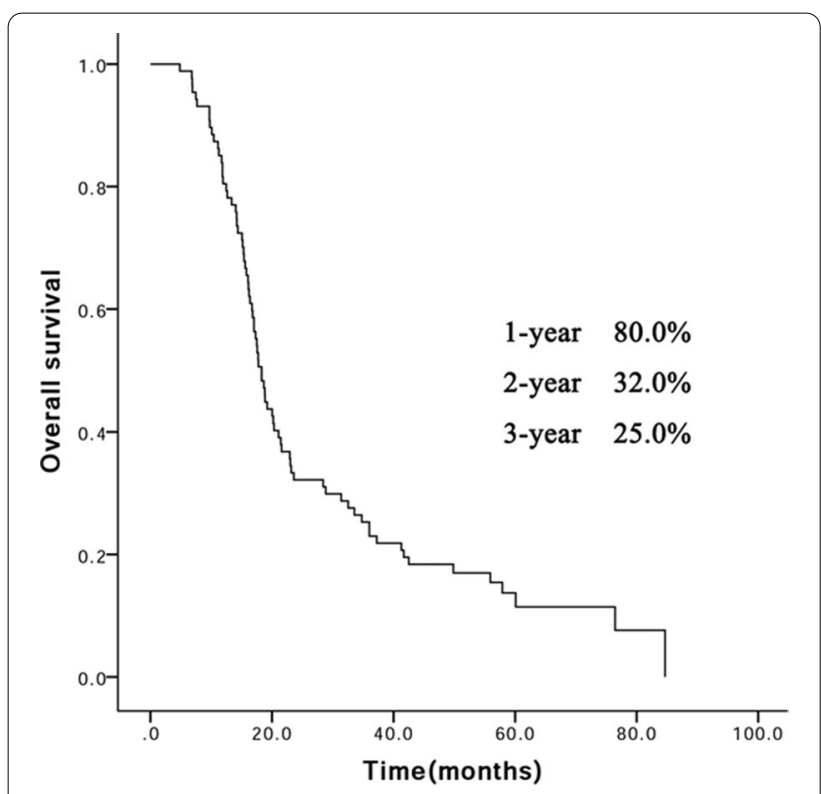

Fig. 2 Survival curve for all patients

was a significant factor influencing the occurrence of grade $\geq 3 \mathrm{RP}$ in lung cancer patients with subclinical ILD. Three of the five patients with grade $5 \mathrm{RP}$ received chemotherapy with gemcitabine before TRT, as did five of the eight patients in whom radiotherapy was discontinued due to the occurrence of grade $\geq 2$ RP. One phase II clinical trial concluded that induction with gemcitabine/carboplatin followed by concurrent paclitaxel/carboplatin with conformal radiation is safe and tolerable [31]. However, this study did not assess whether patients had concomitant pulmonary diseases prior to radiotherapy.

The association between lung cancer and ILD can be explained by shared risk factors such as smoking, and physiopathology caused by fibrogenesis or cancerogenesis [32]. Decision making pertaining to treatment for lung cancer patients with ILD is difficult. The prognosis of these patients appears to be poorer than for those with lung cancer alone [32]. Treatments for lung cancer patients, including resection, chemotherapy, and radiotherapy may trigger severe pulmonary toxicities, such as acute exacerbation or RP [33]. Sato et al. retrospectively analyzed 1763 NSCLC patients with a clinical diagnosis of ILD, and demonstrated 9.3\% acute exacerbation and $43.9 \%$ 30-day mortality after surgical resection [34]. Acute exacerbation of ILD sometimes occurs after chemotherapy for lung cancer [33]. Previous studies have reported that patients with subclinical ILD are more susceptible to developing severe, extensive RP after TRT in lung tumor [10-16, 21, 23]. The classical $\mathrm{RP}$ changes in the lungs have been considered to be confined to the site of irradiation. However, in the early literature, there have been several reports of extensive RP occurring beyond the irradiated field [25, 33, 35]. Although there is currently no clear understanding of the pathophysiology underlying the increased rate and severity of RP in ILD patients, a hypothesis of lymphocyte-mediated hypersensitivity reaction induced by radiation therapy has been postulated [25, 33, 35]. Studies into radiotherapy that triggers severe pulmonary toxicities in these patients are scarce. More data are needed to clarify the mechanisms involved in this phenomenon.

In conclusion, MLD is a significant risk factor for grade $\geq 2 \mathrm{RP}$, and lung cancer patients who have received chemotherapy with gemcitabine in the past, who have V $5 \geq 50 \%$, and those with subclinical ILD involving $\geq 25 \%$ of lung volume have an increased risk of grade $\geq 3 \mathrm{RP}$. The dose-volume parameters should be strictly controlled to ensure the safety of radiotherapy. It is recommended that chemotherapy with gemcitabine be avoided prior to radiotherapy in lung cancer patients with subclinical ILD. Radiation oncologists should carefully select treatments for lung cancer patients with subclinical ILD by considering the clinical characteristics and the IMRTinduced benefits and toxicities.

This study had some limitations. As a single-center retrospective study, with a small sample size and short 
inclusion time, this study may be affected by selection bias and confounding factors. It was difficult to accurately distinguish RP from other types of pneumonitis, because RP is a clinical diagnosis, and can be confounded by preexisting or comorbid disease, including subclinical ILD exacerbations, tumor progression, or infection. The diagnosis of subclinical ILD was based on pretreatment HRCT imaging and was evaluated by a radiologist and two physicians specializing in pulmonology, so subjective judgments made by these individuals may differ. A larger, prospective multi-center study is needed to confirm the conclusions drawn from the data gathered in this study.

\begin{abstract}
Abbreviations
CCRT: Concurrent chemoradiotherapy; Cl: Confidence interval; CTV: Clinical target volume; EQD2: Equivalent dose in 2.0 Gy/(fraction per day); FEV1: Forced expiratory volume in one second; FVC: Forced vital capacity; FVC\%: Percentage forced vital capacity; GTV: Gross tumor volume; HRCT: High-resolution Computed Tomography; ILD: Interstitial lung disease; IMRT: Intensity-modulated radiation therapy; MLD: Mean lung dose; NSCLC: Non-small-cell lung cancer; OS: Overall survival; PTV: Planning target volume; RP: Radiation pneumonitis; RT: Radiation therapy; SBRT: Stereotactic body radiotherapy; SCLC: Small-cell lung cancer; TRT: Thoracic radiation therapy; V5: Percentage of lung volume receiving $\geq 5 \mathrm{~Gy} ; \mathrm{V} 10$ : Percentage of lung volume receiving $\geq 10 \mathrm{~Gy} ; \mathrm{V} 20$ : Percentage of lung volume receiving $\geq 20 \mathrm{~Gy} ; \mathrm{V} 30$ : Percentage of lung volume receiving $\geq 30 \mathrm{~Gy}$; 3D-CRT: Three-dimensional conformal radiotherapy.
\end{abstract}

\section{Acknowledgements}

Not applicable.

\section{Authors' contributions}

Y.X. and S.L. designed the research, interpreted and discussed the results; F.L., H.L., and H.W. collected the data, analyzed the data, wrote the manuscript. All authors read and approved the final manuscript.

\section{Funding}

Not applicable.

\section{Availability of data and materials}

Support data is available to interested readers upon reasonable request to corresponding author.

\section{Declarations}

\section{Ethics approval and consent to participate}

Ethical approval was obtained from the Ethical Review Committee of Shanghai Pulmonary Hospital, Tongji University School of Medicine, China.

\section{Consent for publication}

All authors consented to the publication of the manuscript.

\section{Competing interests}

The authors declare that they have no competing interests.

Received: 6 February 2021 Accepted: 31 March 2021

Published online: 13 April 2021

\section{References}

1. Palma DA, Senan S, Tsujino K, et al. Predicting radiation pneumonitis after chemoradiation therapy for lung cancer: an international individual patient data meta-analysis. Int J Radiat Oncol Biol Phys. 2013;85(2):444-50.

2. Marks LB, Bentzen SM, Deasy JO, et al. Radiation dose volume effects in the lung. Int J Radiat Oncol Biol Phys. 2010;76(3 Suppl):S70-76.

3. Arrieta O, Gallardo-Rincón D, Villarreal-Garza C, et al. High frequency of radiation pneumonitis in patients with locally advanced non-small cell lung cancer treated with concurrent radiotherapy and gemcitabine after induction with gemcitabine and carboplatin. J Thorac Oncol. 2009:4(7):845-52.

4. Meadors M, Floyd J, Perry MC. Pulmonary toxicity of chemotherapy. Semin Oncol. 2006;33(1):98-105.

5. Zhang XJ, Sun JG, Sun J, et al. Prediction of radiation pneumonitis in lung cancer patients: a systematic review. J Cancer Res Clin Oncol. 2012;138(12):2103-2016.

6. Dang J, Li G, Zang S, et al. Risk and predictors for early radiation pneumonitis in patients with stage III non-small cell lung cancer treated with concurrent or sequential chemoradiotherapy. Radiat Oncol. 2014;9:172.

7. Leprieur EG, Fernandez D, Chatellier G, et al. Acute radiation pneumonitis after conformational radiotherapy for non-small cell lung cancer: clinical, dosimetric, and associated-treatment risk factors. J Cancer Res Ther. 2013;9(3):447-51.

8. Baker R, Han G, Sarangkasiri S, et al. Clinical and dosimetric predictors of radiation pneumonitis in a large series of patients treated with stereotactic body radiation therapy to the lung. Int J Radiat Oncol Biol Phys. 2013;85:190-5.

9. Torre-Bouscoulet L, Muñoz-Montaño WR, Martínez-Briseño D, et al. Abnormal pulmonary function tests predict the development of radiation-induced pneumonitis in advanced non-small cell lung cancer. Respir Res. 2018;19:72.

10. Yamaguchi S, Ohguri T, Matsuki Y, et al. Radiotherapy for thoracic tumors: association between subclinical interstitial lung disease and fatal radiation pneumonitis. Int J Clin Oncol. 2015;20(1):45-52.

11. Ueki N, Matsuo Y, Togashi Y, et al. Impact of pretreatment interstitial lung disease on radiation pneumonitis and survival after stereotactic body radiation therapy for lung cancer. J Thorac Oncol. 2015;10:116-25.

12. Lee YH, Kim YS, Lee SN, et al. Interstitial lung change in pre-radiation therapy computed tomography is a risk factor for severe radiation pneumonitis. Cancer Res Treat. 2015;47(4):676-86.

13. Li F, Zhou Z, Wu A, et al. Preexisting radiological interstitial lung abnormalities are a risk factor for severe radiation pneumonitis in patients with small-cell lung cancer after thoracic radiation therapy. Radiat Oncol. 2018;13:82.

14. Chen H, Senan S, Nossent EJ, et al. Treatment-related toxicity in patients with early-stage non-small cell lung cancer and co-existing interstitial lung disease: a systematic review. Int J Radiat Oncol Biol Phys. 2017;98(3):622-31.

15. Onishi H, Yamashita H, Shioyama Y, et al. Stereotactic body radiation therapy for patients with pulmonary interstitial change: high incidence of fatal radiation pneumonitis in a retrospective multi-institutional study. Cancers (Basel). 2018;10(8):257.

16. Goodman CD, Nijman SF, Senan S, et al. A Primer on Interstitial Lung Disease and Thoracic Radiation. J Thorac Oncol. 2020;15(6):902-13.

17. Yamashita H, Kobayashi-Shibata S, Terahara A, et al. Prescreening based on the presence of CT-scan abnormalities and biomarkers (KL-6 and SP-D) may reduce severe radiation pneumonitis after stereotactic radiotherapy. Radiat Oncol. 2010;5:32.

18. Doyle TJ, Hunninghake GM, Rosas IO. Subclinical interstitial lung disease: why you should care. Am J Respir Crit Care Med. 2012;185:1147-53.

19. Travis WD, Costabel U, Hansell DM, et al. An official American Thoracic Society/European Respiratory Society statement: update of the international multidisciplinary classification of the idiopathic interstitial pneumonias. Am J Respir Crit Care Med. 2013;188:733-48.

20. Glick D, Lyen $S$, Kandel S, et al. Impact of pretreatment interstitial lung disease on radiation pneumonitis and survival in patients treated with lung stereotactic body radiation therapy (SBRT). Clin Lung Cancer. 2018;19(2):e219-226.

21. Yamaguchi S, Ohguri T, Ide S, et al. Stereotactic body radiotherapy for lung tumors in patients with subclinical interstitial lung disease: the potential risk of extensive radiation pneumonitis. Lung Cancer. 2013;82:260-5. 
22. Sanuki N, Ono A, Komatsu E, et al. Association of computed tomography-detected pulmonary interstitial changes with severe radiation pneumonitis for patients treated with thoracic radiotherapy. J Radiat Res. 2012;53(1):110-6.

23. Niska JR, Schild SE, Rule WG, Daninels TB, Jett JR. Fatal radiation pneumonitis in patients with subclinical interstitial lung disease. Clin Lung Cancer. 2018;19(4):E417-20.

24. Kim H, Pyo H, Noh JM, et al. Preliminary result of definitive radiotherapy in patients with non-small cell lung cancer who have underlying idiopathic pulmonary fibrosis: Comparison between X-ray and proton therapy. Radiat Oncol. 2019;14:19.

25. Bahig H, Filion E, Vu T, et al. Severe radiation pneumonitis after lung stereotactic ablative radiation therapy in patients with interstitial lung disease. Pract Radiat Oncol. 2016;6(5):367-74.

26. Washko GR, Lynch DA, Matsuoka S, et al. Identification of early interstitial lung disease in smokers from the COPDGene Study. Acad Radiol. 2010;17(1):48-53.

27. Okubo M, Itonaga T, Saito T, et al. Predicting risk factors for radiation pneumonitis after stereotactic body radiation therapy for primary or metastatic lung tumours. Br J Radiol. 2017;90(1073):20160508.

28. Nakajima M, Yamamoto N, Hayashi K, et al. Carbon-ion radiotherapy for non-small cell lung cancer with interstitial lung disease: a retrospective analysis. Radiat Oncol. 2017;12:144.

29. Onishi H, Yamashita H, Shioyama Y, et al. Stereotactic body radiation therapy for patients with pulmonary interstitial change: high incidence of fatal radiation pneumonitis in a retrospective multi-institutional study. Cancers. 2018;10(8):257.
30. Ozawa Y, Abe T, Omae M, et al. Impact of preexisting interstitial lung disease on acute, extensive radiation pneumonitis: retrospective analysis of patients with lung cancer. PLoS ONE. 2015;10:e0140437.

31. Bepler $\mathrm{G}$, Dilling TJ, Wagner $\mathrm{H}$, et al. Phase II trial of induction gemcitabine and carboplatin followed by conformal thoracic radiation to 74 Gy with weekly paclitaxel and carboplatin in unresectable stage III non-small cell lung cancer. J Thorac Oncol. 2011;6(3):553-8.

32. Naccache JM, Gibiot Q, Monnet I, et al. Lung cancer and interstitial lung disease: a literature review. J Thorac Dis. 2018;10(6):3829-44.

33. Tsurugai $Y$, Takeda A, Sanuki N, et al. Stereotactic body radiotherapy for lung cancer patients with idiopathic interstitial pneumonias. Radiother Oncol. 2017;125(2):310-6.

34. Sato T, Teramukai S, Kondo H, et al. Impact and predictors of acute exacerbation of interstitial lung diseases after pulmonary resection for lung cancer. J Thorac Cardiovasc Surg. 2014;147(5):1604-1611.e3.

35. Morgan G, Breit S. Radiation and the lung: a re-evaluation of the mechanisms mediating pulmonary injury. Int J Radiat Oncol Biol Phys. 1995;31(2):361-9.

\section{Publisher's Note}

Springer Nature remains neutral with regard to jurisdictional claims in published maps and institutional affiliations. 